\title{
IJTARP
}

$11(1), 75$

International Journal of Transactional Analysis

Research \& Practice

https://doi.org/10.29044/v11i1p75

\section{Strokes, games and learning in groups}

\author{
(C) 2020 Piotr Jusik
}

We thank the previous publishers for permission to republish this article, which previously appeared as Jusik, P. (2018) Strokes, games and learning in groups. Edukacyjna Analiza Transakcyjna, 7, 27-36. We have retained the structure and referencing of that article.

\section{Summary}

Students' hunger for strokes plays a key role in improving learning outcomes and emotional literacy in groups. Teachers and facilitators can consciously respond to their learner's need for recognition by paying attention to the group culture and creating a responsive environment through modelling. When learners' hunger for strokes is unmet, they start inviting psychological games. Teachers can respond adequately by stressing options in relation to the drama triangle. Additionally, TA concepts are more effective when applied in a relationship context, as otherwise the interventions become a fruitless, simplistic and formulaic endeavour. Some group settings give rise to the role lock phenomenon, when an individual represents an issue that is collectively avoided by other members. When this is brought into awareness, the group can move forward. On the whole, learners thrive when they receive appropriate strokes and permissions that support their growth and development.

\section{Keywords}

recognition hunger, psychological games, group dynamics.

\section{Introduction}

Transactional analysis (TA) was initially developed as a method of working with groups. For many TA practitioners, it is important to expand their perspective from individual psychology to group dynamics. This is especially relevant to the transactional analysts in training that are acquiring not only the cognitive skills, but also learn how to hold and contain groups. This article is a personal account of applying stroke economy (Steiner, 1971, p. 9-15) and game theory (Berne, 1964, p. 44-58, Karpman, 1968, p. 39-43) during the author's three-year teaching experience in a pupil referral unit in London. The concepts of strokes and games will be reviewed, taking into consideration how these can potentially inform educational practice and influence thinking and interventions relevant to a schooling environment.

\section{Theoretical underpinnings of stroking}

The hunger for strokes is one of the central cornerstones of TA as underlined by Steiner (1971, p. 9): "strokes are as necessary to human life as are other primary biological needs such as food, water, and shelter - needs which if not satisfied will lead to death". The works of Spitz (1945, p. 53-74) suggested that sensory and more importantly emotional deprivation can lead to the "shrivelling of the spinal cord" (Berne, 1964, p. 14), which can manifest as apathy and degenerative changes in the nervous system.

Berne (1964, p. 15) defines a stroke as "a fundamental unit of social action". In classroom practice, stroking refers to the way the individuals involved in the learning process give each other recognition. This recognition may refer to aspects of being ("You are such a kind person") or doing ("Good work") through verbal (words) and non-verbal (smile) channels of communication. Some TA practitioners state that every transaction is a stroke, but not every stroke is a transaction. Thus, a teacher or learner can give others positive (pleasant) or negative (unpleasant) strokes based on the receivers being (unconditional) or behaviour (conditional) through a combination of verbal and non-verbal messages. As we grow up our needs for recognition become more complex and the aforementioned social action gives rise to the dynamics in couples and groups.

Berne claimed that in the absence of positive recognition humans unconsciously create situations that provide drama and excitement. The world of psychology realised that humans are so dependent on stimulation and will seek at all cost, also through manipulative strategies, to satisfy this need. This is relevant to a classroom because a teacher can 
ascertain the learners' authentic recognition needs to prevent games and promote autonomy.

The stroking environment needs to be well understood to facilitate learning and development. In an increasingly diverse world the meaning of strokes is determined by culture (e.g. nodding or raising the tone of voice may mean something different in Poland or India). At the same time, the hunger for recognition drives our behaviour and may thus be considered universal. The need for strokes is a powerful factor that shapes the dynamics of groups and plays a role in maintaining the status quo: "Indeed, solitary confinement is one of the punishments most dreaded even by prisoners hardened to physical brutality, and is now a notorious procedure for inducing political compliance" (Berne, 1964, p. 13). Claude Steiner deconstructs socially held beliefs underlying stroke exchange in his article entitled 'The stroke economy' (1971, p. 11). He emphasised the need to re-evaluate "the basic training regarding the exchange of strokes" (Steiner, 1971, p. 9) to create conditions for autonomy. The following stories and examples will illustrate how teachers or facilitators can apply some TA concepts to improve learning outcomes and model emotional literacy.

\section{Applying stroking theory in educational practice}

Transactional analysts that lead or facilitate a group need to be mindful of the stroking patters that are characteristic to that group. For instance, in his teaching role, the author faced young people that came from deprived and sometimes criminal environments. Some of their language was quite revolting and yet it was important to understand that it was part of their culture. They may have been calling each other horrible names and it seemed to be completely normal to them. In such an environment, a teacher cannot start speaking the Queen's English and invite a very sophisticated stroke exchange, i.e."I have been struck by the complexity of your passage". It is more appropriate to say "That's a pretty cool passage, mate coz [because] you used two ideas from the text." Another example occurred at a behaviour management workshop for educators. The task was to use some swear words to explore the difficulty of radically changing one's stroking pattern. The group consisted of fairly middle class and educated women. We did not even go that far in the exercise to even say the word $c^{* *}$ aloud. Following the session, the author realised the importance of the group's specific stroking patterns, which required preparation beforehand.

Furthermore, it is essential to understand fully what the stroke means at the psychological level. When the author turned thirty he had a birthday party organised by his tutor group. The youngsters decided to gift a 'lovely' card with the words shown in Figure 1. The stroke could have been understood very literally ('you are a mug!'), however the colours and tone of the card implies some affection. Therefore, the context, tone, and form play a crucial role in determining the psychological meaning of the stroke. On the other hand, it was equally apparent that the staff in the pupil referral unit became desensitised and accepted some of the persistently negative stroking as 'normal'. On one occasion a social worker observed one of the author's lessons. She was quite taken aback and commented on the situation: "You are so vulnerable". This suggests that teachers can be institutionalised and their judgement can be clouded by passivity, notably by overadaptation (Pierzchała, 2013, p. 238246). Therefore, a transactional analyst working in education needs to think about stroking patterns, identify what is considered the norm and elicit appropriate meaning based on the cultural script (Roberts, 1971, p. 33) of the client group.

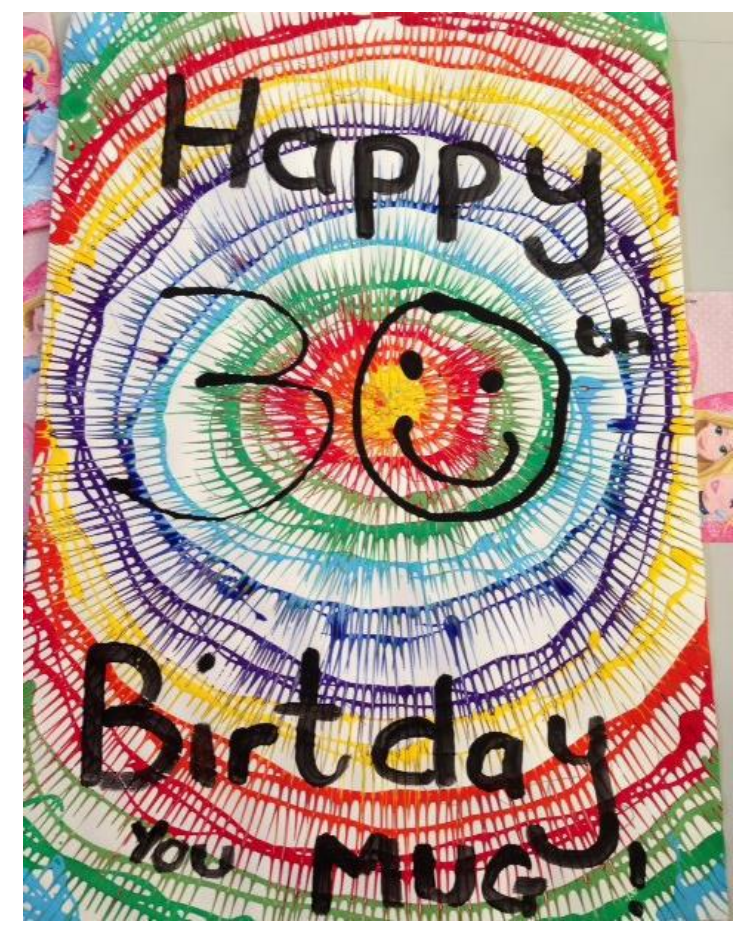

Figure 1: A birthday card given to the author by his tutor group

\section{Analysis of transactions that create a stroke rich classroom}

Teachers that consciously provide relevant strokes will create conditions for achievement. Steiner (1971, p. 11-12) describes a situation in society whereby many individuals are stroke deprived because someone holds the monopoly for stroke provision and exchange. A group leader or teacher provides recognition for thinking that at some level creates the student's perceived learning capability. Many pupils come to a pupil referral unit holding negative projections 
concerning education and often display their P2 [Parent] transference (Moiso, 1985, p. 197) resulting from their relationships with previous teachers. In other words, the pupils believe that teachers are critical and dismissive of them, so they easily give up. One way of increasing student motivation is to explicitly state that strokes are available in abundance in the classroom. This was evident when the author witnessed the following transactions (Functional ego states as described by Stewart, Joines, 2009, p. 230-31):

Student: $F^{\star}$ cking hell, I can't be bothered. Science is shit! (-AC $\rightarrow-C P)$

Teacher: That's fine, you can feel your anger. $(\mathbf{A} \rightarrow \mathbf{A}$; ulterior: $+\mathbf{N P} \rightarrow+\mathrm{FC}$ )

Student: What the f $^{*} \mathrm{ck}$ ? (-AC $\rightarrow-\mathrm{CP}$; ulterior $+\mathrm{FC} \rightarrow$ +NP - need for containment)

Teacher: I can hold this for you. (+NP $\rightarrow+\mathbf{F C})$

Student: Hold what? $(\mathbf{A} \rightarrow \mathbf{A}$; ulterior $+\mathbf{F C} \rightarrow+\mathbf{N P}$ )

Teacher: Hold the hope. $(\mathbf{A} \rightarrow \mathbf{A}$; ulterior $+\mathbf{N P} \rightarrow+\mathbf{F C})$

Student: Hope for what?! $(\mathbf{A} \rightarrow \mathbf{A}$; ulterior $+\mathbf{F C} \rightarrow$ +NP)

Teacher: Hope for your success. (A $\rightarrow \mathbf{A}$; ulterior: $+\mathrm{NP} \rightarrow+\mathbf{F C}$ )

This way of crossing transactions suggests to the learner that all sorts of strokes are available, rather than the negative ones that the learner was used to before. Since according to Steiner "Most human beings live in a state of stroke deficit" (Steiner, 1971, p. 12), the teacher needs to consider the area of deficit in the groups or classes taught. A number of young people in a pupil referral unit have special needs that stem from an invalidating home environment. On one occasion a student expressed himself with the following words: "I f*cking hate you, you're a pr** $k$ " to which the author replied: "That's fine. I suppose you can trust your feelings because they are important. And I'm not here to be liked". This way a teacher can respond to the pupil's need for mirroring and give the young person some recognition of their emotional response, draw boundaries and give them permission to feel.

\section{Holding and containing in educational practice}

Parents of students excluded from school are also a group of clients that benefit from receiving appropriate strokes. There is often quite a lot of internal conflict at home and the parents feel hopeless at times. Their stroking environment may constitute quarrels and mutual accusations. They have been recognised for being 'not good enough' and frequently labelled as 'failing parents'. Talking with parents over the phone is an opportunity to provide them with adequate strokes.
For instance, offering parents mindful presence and attention as well as allowing them to speak freely helps them to find their Adult ego state (Tudor and Summers, 2000 , p. 26). At the same time, stroking their efforts to contain their child despite the difficulties they face, boosts their sense of agency. For instance, the Author used to work with a family where the mother was quite ill (systemic inflammation and on steroids). It was vital to contain her anxiety and build a working alliance where she could off-load some of her difficulties. The following words were used often: "You're doing the best you can". This gave this mother some sense of validity and the feeling of being heard in the education system. Over many months, she managed to find motivation to keep her son at school and supported him to find vocational training. Thus, when parents/carers feel held and contained during moments of challenge, it has a positive impact on the learner.

A leader creates stroking patterns in groups by establishing norms through modelling. A teacher can encourage the learners to exchange positive strokes by setting tasks such as: "What are two good things about your classmate's work?" Negative unconditional strokes (e.g. $F^{\star *} k$ you!) should always be named and challenged by handing back responsibility to the student: "What is it that makes you want to put him/her down?" Another example of modelling occurred during a personal development workshop in Ukraine. The author thanked the group members for being on time and adhering to the agreed schedule. One of the members said that they felt this exchange was inauthentic. The author recognised their courage for speaking up and they were invited then to check their feelings with the facilitator throughout the workshop. This was a new experience for the participants because in Ukraine the education system tends to encourage overadaptation. However, this instance exemplifies that creating new stroking patterns in groups can empower learners. According to the author's international teaching experience, in many schools it is unthinkable to speak up and express disagreement with the teacher. It relates to Steiner's point (Steiner, 1971, p. 13-14) that the flow of strokes is generally restricted in society and often used as a regulatory mechanism: "The end result is that the most human of capacities, the capacity to love, is taken away from people and then turned against them by using it as a means to bring about certain desired behaviour". In contrast, a wise teacher can model a free exchange of strokes and thus build the student's intrinsic motivation that is not limited by beliefs of the stroke economy. As a result, the learners will feel held and contained in their Child ego state, which decreases their anxiety and enables them to access their full Adult thinking capacities. 


\section{Addressing games in educational practice}

Humans are dependent on recognition that we prefer to provoke negative strokes in the absence of positive ones. This is one of the benefits of psychological games because they can potentially provide an unlimited supply of strokes (Stewart and Joines, 2009, p. 250-268). However, these repetitive patterns of behaviour limit our options and our capacity for autonomy. One way of supporting learners is based on recognising and confronting games in the classroom this is where the potential for student selfdetermination and autonomy lies.

Classroom practitioners can face numerous game invitations throughout the course of their day. An autonomy-supportive teacher can stress the learner's ability to perceive options and to act on them. The drama triangle (Karpman, 1968, p.40) is a very elegant tool to make meaning of and envisage the direction of psychological games. For instance, the following situation occurred during a year nine Science class in a pupil referral unit: two boys recently excluded from main-stream education due to their behaviour had to jump for a minute to evaluate their fitness. One of the boys was annoyingly counting aloud and inviting the other to persecute him ('Kick me!'). As predicted, the other boy lost his temper and was about to start a fight ('l've got you!'). They were separated and after some name calling they settled. They were clearly asked:

'What did you learn through this situation?' and 'What other things can you do in the future?'

They boys seemed receptive and gave the following answers:

Persecutor role: "I can tell him earlier that he annoys me!"

Victim role: "I can keep quiet not to annoy him."

It is evident that stressing student options helps to intervene without persecuting ("It's your fault!") or rescuing ("Oh, poor you!") while awareness of the drama triangle enables us to predict classroom dynamics.

At the same time, there are some students that have little Adult available and their need to engage in games is so strong and it is impossible to contain the process at hand. The drama triangle can be a powerful tool, provided that there is enough awareness and capacity for reflection on the part of the learner. It requires all of the parties to look at themselves and acknowledge their position at the psychological level. It may not be useful with pupils in altered states of consciousness, such as rage or strong anxiety. Sometimes, it is necessary to treat this concept as a loose map and intervene from a position of integrity and sometimes 'play' along with others using Adult awareness. This enables contact with the learners in a familiar way. Once there is enough relationship, it is possible to work in and out of transference to reveal the relational patterns. For example, the author's experience suggests that some students were able to gradually take responsibility for their role in the drama triangle, however that could sometimes take some eighteen months.

Additionally, TA game theory can be interpreted as a quite structured system. Using these concepts too rigidly could limit options of developing really meaningful relationships. The drama triangle is a model; however models do not reflect reality and, as such, have their own limits. This is significant for teachers trained in science and mathematical disciplines that rely on structure and predictability based on observable phenomena. They might have a tendency to use thinking and over-structuring as a defence mechanism. Additionally, TA might appear simplistic through its diagrams and straightforward language. It is therefore important that TA applied in the classroom does not become yet another scientific endeavour, but a relational and human to human experience that is based on mutual impact.

This becomes quite apparent whilst dealing with groups when one member keeps raising an issue which leads the group to become stuck in gamey patterns. Facilitators or teachers work with a number of different participants that co-create a certain 'metaentity', that is the 'it' that is more than the sum of all members and their individual proclivities. This makes game analysis difficult due to the emergent complexities of the co-created dynamics. Charlotte Sills (2003, p. 283-284) describes groups that become stuck in games and unconsciously avoid facing what is difficult for them, i.e. some existential question that was not addressed in the family of origin. Individuals are trying to resolve their personal paradox that stems from their unmet relational needs and this way they keep repeating their maladjusted patterns. Since the need to resolve the issue is so strong, it keeps coming back and is raised by 'the difficult one': a group member, whose intrapsychic impasse concerns the same issue, experiences the evocation of an archaic or introjected ego state that then recreates the early field condition. He or she steps into the role (Sills, 2003, p. 283).

This process gives rise to what is called 'role lock' and is a way avoiding the uncomfortable situation and the tension associated with the unresolved paradox. In order for the group to become authentic there are two major milestones:

- The group needs to release the individual from the role and own some aspects of the issue as it belongs to the group; 
- The individual needs to decide to let go off the issue and the compulsion to repeat.

Translating this into daily teaching practice, it becomes clear how 'useful' it is for class members to blame one pupil amongst them in order to avoid any discomfort associated with the situation at hand. Some good students at school are sometimes seen as a 'neek' (someone who is carrying out their work diligently) and this helps others to avoid their inadequacy as a learner. The disengaged students can project their disowned feelings of inadequacy onto the good student to feel OK. However, the 'neek' tends to see school recognition as a main sources of their adequacy. Thus, the existential question is about OKness and the feelings of worth and dignity: "How do I behave to receive strokes?" or "Am I worthy of strokes in the first place?" Again, a wise teacher can nudge the students to consider their real motives and model a free exchange of strokes. However, since the groups in a pupil referral unit have an educational purpose mainly, rather than a therapeutic one, role lock theory can be used only to some extent. It certainly allows the teacher to recognise the disavowed aspects in the group dynamics and gently bring them into awareness. On the other hand, given the contract with the institution and the limited availability of the Adult ego state (Tudor and Summers, 2000 , p. 26) in many pupil referral units, it seems inappropriate to delve too much into classroom psychodynamics. It is more beneficial to consider the developmental stages of the group members (LevinLandheer, 1982, p. 138) and provide them with suitable permissions and strokes that support learners:

- to exist, to live and to be

- to act, to do things

- to think, using logic and concepts

- to have an identity and know who we are

- to develop skilfulness through structures and values

- to regenerate, producing life anew, and

- to recycle, developing effectiveness at every age.

These strokes potentially enhance Adult awareness and increase the students' perceived and real learning capability.

\section{Conclusion}

In conclusion, teachers applying TA concepts in their work are in a position to satisfy some of their students' needs for recognition. Educators who accurately perceive the stroking patterns of the groups they teach are able to fully grasp the co-created learning culture. Furthermore, raising awareness of games using the drama triangle helps to promote autonomy, as long as it is considered in a relational context. Otherwise, TA can lose its potency and become only a formulaic description based on diagrams. Some games unfold at the whole group arena, leading to a role lock. This situation requires the practitioner to consider the existential question that is crucial for the group to move forward. All in all, creating a stroke-rich environment that responds to development needs of the group can reduce games and contribute to a climate of achievement and autonomy.

Piotr Jusik is in training to become a Certified Transactional Analyst in the Counselling field. He is engaged in research that spans Guatemala, the UK, Poland and Ukraine and is the National Co-ordinator in Guatemala for the TA Proficiency Awards. He can be contacted on peter@iflowcoaching.com

\section{Bibliography}

Berne, E. (1964). Games people play. New York: Grove Press, Inc.

Karpman, S.B. (1968). Fairytales and script drama analysis. Transactional Analysis Bulletin, 7 (26), 39-43.

Levin-Landheer, P. (1982). The Cycle of Development.

Transactional Analysis Journal, 12 (2), 129-139. https://doi.org/10.1177/036215378201200207

Moiso, C. (1985). Ego States and Transference. Transactional Analysis Journal, 15 (3), 194-201. https://doi.org/10.1177/036215378501500302

Napper, R.\& Newton, T. (2014). Tactics: Transactional analysis concepts for all trainers, teachers and tutors plus insight into collaborative learning strategies. Ipswich: TA Resources.

Pierzchała, A. (2013). Pasywność w szkole: Diagnoza zjawiska z punktu widzenia analizy transakcyjnej. Częstochowa: Wydawnictwo im. Stanisława Podobińskiego Akademii im. Jana Długosza.

Roberts, D.L. (1975). Treatment of Cultural Scripts. Transactional Analysis Bulletin, 5 (1), 29-35. https://doi.org/10.1177/036215377500500106

Sills, C. (2003). Role Lock: When the Whole Group Plays a Game. Transactional Analysis Journal, 33 (4), 282-287. https://doi.org/10.1177/036215370303300403

Spitz, R.A. (1945). Hospitalism. The Psychoanalytic Study of the Child, 1 (1), 53-74

https://doi.org/10.1080/00797308.1945.11823126

Steiner, C. (1971). The Stroke Economy. Transactional

Analysis Journal, 1 (3) 9-15

https://doi.org/10.1177/036215377100100305

Stewart I.\& Joines V. (2009). TA Today. A New Introduction to Transactional Analysis, Nottingham, England and Chapel Hill, NC: Lifespace Publishing

Summers, G.\& Tudor, K. (2000). Co-creative. Transactional Analysis Journal, 30 (1), 23-40. https://doi.org/10.1177/036215370003000104 